\title{
Editors' Introduction: Presenting Writing Assignments as Intellectual Work and as Disciplinary Practice
}

\author{
Susanne Hall, California Institute of Technology \\ Jonathan Dueck, The George Washington University
}

January 1, 2017

\begin{abstract}
We are proud to publish our debut issue of Prompt, a multidisciplinary journal focused specifically on collegiate writing assignments. This journal highlights the pedagogical process of crafting writing assignments and offers contextualized reflections on teaching writing in varied disciplines. In this first editor's introductory essay, we reflect on our process for developing the journal and offer a brief overview of the five essays and assignments that make up this first issue.
\end{abstract}

\section{The origin story of Prompt}

The early origins of Prompt lie in a Writing in the Disciplines (WID) project we were a part of at Duke University while we were postdoctoral fellows in Duke's Thompson Writing Program. At Duke, first Susanne (2011-12) and then Jon (2012-13) held the position of Assistant Director of Writing in the Disciplines. Our role in this position was to support the teaching and learning of writing in disciplinary courses across the university, primarily by working with the faculty teaching those courses. Working under the direction of Cary Moskovitz, then and now Duke's Director of Writing in the Disciplines, we created an online project we called the "WID Gallery." The goal of this gallery was to create a digital space to display annotated writing assignments from across disciplines. This space would, we hoped, directly assist us in our WID work at Duke, and our primary intended audience for this website was Duke faculty, post-docs, and graduate students.

We planned for the gallery to serve several functions. First, it could be a durable archive for the writing assignments we supported our faculty in developing, preserving them in one place that we could consult into the future. Next, once populated with enough content, it could be a reference point for discussions with faculty interested in making 
changes to their teaching of writing or teaching with writing, providing examples of what their colleagues were doing across the university. Finally, working with faculty to annotate their assignments for the gallery was itself an instructive activity, for both them and us, and it was a process that enriched relationships and deepened our knowledge about the teaching and learning of writing.

The WID Gallery started as a local resource that began to accomplish all of these goals. As we both moved on to faculty positions at other universities, the idea of the Gallery stayed with us. We were both undertaking WID work of various kinds at our new institutions, and we found ourselves wishing that that some kind of multi-institutional WID Gallery existed, so that we could examine and share high quality, contextualized writing assignments from across fields, courses, and universities. So, we did what one does in the age of the internet when one thinks, "I wish X existed"-we assumed it already did and started searching for it online.

We found that college writing assignments were circulating in at least five ways, all of which were compelling, and none of which satisfied us fully. First, they are traded informally between colleagues. Over lunch, one person mentions an assignment that works, the other is interested, and an email with an attachment is sent. We saw this happening all the time during our postdoctoral experience at Duke. We knew this personal network of exchange, while terrifically valuable to those involved in it, to be highly idiosyncratic and inaccessible to outsiders.

Second, faculty who blog about their teaching sometimes discuss and share writing assignments in those venues. While this opens up the conversation, it is difficult to locate these assignments unless one is directed to them by an existing relationship with the blog or an announcement on Twitter or Facebook. Our access to assignments shared in that way is still fundamentally limited by our personal networks. Some academics cultivate expansive in-person and online networks, but many lack the time or resources to do this. It also seems to us that the golden age of academic blogging may be behind us, and that we now see less of this kind of writing than we used to.

A third place where writing assignments are shared and discussed, we well knew, is in research in the fields of writing studies (also often called "composition") and education, where these assignments can be objects of study. One can find one's way to this writing about assignments through database search tools, so locating them is relatively easy with the right search terms. (The glossary term "assignment" on CompPile.org is a good starting place.) However, research by a scholar on the assignments and related student writing of other instructors may not present individual assignments to readers, at least not in their entirety. Further, key disciplinary and pedagogical contexts for the assignments are often obscured when assignments are the subject of another scholar's research, especially if those contexts fall outside the research question being pursued. How was this assignment developed and revised? What questions in one's field does it address? How did students affect the shaping of this assignment over time? These are critical questions best answered by the assignment-writers themselves. 
Fourth, there are a few online repositories for assignments. But here, we found several limits. The first is that the repositories are not actively curated, at least not by standards that were visible to us. This means that the quality of the material can be variable. Furthermore, since submissions to repositories rely upon the goodwill of instructors who make time to share their work, the amount of work shared and frequency of updates is low. The WAC Clearinghouse's Teaching Exchange (http: //wac.colostate.edu/teaching/index.cfm?category $=5$ ) offers a case in point here; it is promising space located in a larger project that is rich with resources for teachers of writing. As of this writing, though, the Exchange offers a relatively small set of assignments and is not frequently updated. Another limit of these voluntary repositories is that assignments are typically shared without annotation or commentary, leaving an outsider to the course to guess about the contexts in which the assignment has been developed and taught.

There is one interesting development on the horizon here: the online Commons Open Repository Exchange (CORE), a part of the Modern Language Association (MLA) Commons, now in Beta. (The MLA is the professional organization for scholars and teachers of language and literature.) The CORE is "a library-quality repository for sharing, discovering, retrieving, and archiving digital work" (https://commons.mla.org/core/). At present, most of the work uploaded to the CORE seems to focus on research rather than teaching, but there is some pedagogical material in the repository. This repository project suggests that that interest in sharing pedagogical materials may be growing, and we are optimistic that a greater volume of teaching-related materials may eventually be shared through the CORE. At present, anyone can read the contents of CORE online, but only MLA members can post to it, which means that there are both disciplinary and financial limits on wider participation. We wonder if the materials will remain publically available if the project moves beyond beta testing, and, since the project is funded by a National Endowment for the Humanities start-up grant, the funding for a movement beyond beta cannot be assumed. Beyond these possible limitations, the repository limits we noted above - lack of curation standards and little or no annotation or commentary - seem unlikely to differ in the CORE.

Fifth, and finally, writing assignments are shared by their authors in peer-reviewed pedagogy-focused journals in a number of fields. For example, the disciplinary pedagogy journal Primus: Problems, Resources, and Issues in Mathematics Undergraduate Studies (http://www.tandfonline.com/toc/upri20/current) and the interdisciplinary pedagogy Journal for Excellence in College Teaching (http://celt.miamioh.edu/ject/about.php) both publish first-person articles on writing assignments, in which the author presents a successful assignment and analyzes the reasons for its success. These articles really excited us, and here we felt we had found what we were looking for-access to the assignments themselves, rich writing about the assignments by the faculty who created them, and curation through the peer-reviewed editorial process. The quality was good because faculty were able to take the time to do this work, because it could be recognized by our institutional system of carrots and sticks that so heavily rewards publication in scholarly 
journals. These assignments had some degree of searchability through disciplinary journal databases, though it helps to know the names of pedagogy journals. Within one's home discipline, this is approachable, but if one is a WID specialist looking for assignments in varied fields, that is a long list of journals with which to be familiar and able to locate. The crucial remaining limit was that the journals published only a small number of pieces on writing assignments, because they are, of course, also focused on the many other important aspects of college teaching. It is also worth mentioning the majority of these pedagogy-focused journals are not open-access.

On reflection, we knew what should exist, but did not yet - a multidisciplinary, peerreviewed, open-access academic journal that focused on college writing assignments. The result of that realization, and several years of hard work between that moment and this, is this online, open-access journal: Prompt.

\section{What is a prompt?}

Our understanding of what an effective writing assignment is and does is deeply indebted to scholarship in writing studies on the teaching of writing, mentorship we have received, long experience in the classroom, and our respective disciplinary training (Jon's in ethnomusicology and Susanne's in literature). We intend for Prompt to find a truly multidisciplinary readership, and we anticipate that many of our authors and readers will be influenced by diverse scholarship, varied mentorship, classroom experiences of distinct types, and different disciplinary training. Rather than advance some kind of unified theory of writing assignments here, in our introductory essay, we intend that the work of the journal over the years ahead-our work as editors, as well as that of our contributors - will be to encourage a collaborative, complex, and multifarious understanding and theorization of the effective writing assignment.

We recognize that the term "prompt" is not used to describe a writing assignment in all fields, but we chose it as a title for this journal because we believe it embodies something fundamental about the role of a writing assignment across disciplines. Bound up in the term prompt are the two ideas, somewhat in tension with one another, of assisting someone and inciting them to action. This is most fundamentally what a writing assignment does, we think, regardless of whether the student is being asked to write about poetry, programming, or poverty, or whether they are writing a technical report or a concert review. It scaffolds students' work, offering them somewhere to start, a goal, and some raw materials. At the same time, it throws students forward, asking them to grapple with new ideas, methods, and materials. Striking this balance, between assisting and inciting, is not easy, and the balance must be recalibrated with each course and assignment.

Developing a writing assignment also requires that we martial our disciplinary research and knowledge as well as our pedagogical study and experiences. In addition to introducing students to an area of inquiry, we introduce them to our discipline's ways of asking and answering questions about that topic. Further, we must consider how to mediate 
between our own ways of writing to colleagues inside our disciplines - practices and poses internalized so fully that many of us have trouble imagining how else things could be done - and students' diverse experiences with college writing in many, varied disciplines. This work requires continuous critical thought, experimentation, and self-assessment. It is deeply intellectual work that deserves to be shared outside the classroom, both as a scholarly achievement in its own right, and also because it is of clear, practical use to our colleagues. We hope that the existence of our journal inspires outstanding teachers to share that intellectual work outside their classrooms. As the journal grows, we hope to make room for dialogue within the pages of of the journal itself. For example, we look forward to the opportunity to one day publish writing assignments that have been themselves inspired by earlier publications in the journal. This, then, is a secondary reason to choose the title Prompt for this journal - we hope it incites and scaffolds an interdisciplinary, scholarly conversation about pedagogy between college instructors who may not otherwise find themselves with a chance to share such ideas with one another.

\section{Prompt journal format}

Prompt publishes articles that present and explain specific successful college writing assignments. Our mission is to promote the critical circulation of a wide variety of assignments, and this includes disciplinary diversity and diverse kinds of innovation. This journal reflects our backgrounds as WID specialists with interests in disciplinary difference, as well as an awareness of the generative work that can happen when we share and discuss those differences. We have endeavored to publish assignment writers from across a spectrum of fields to tell our readership, in terms that make sense in their own disciplinary contexts, about how they teach writing in their best assignments.

In order to accomplish this, we have asked our authors to write a short essay describing the key ideas of their assignment, their process of creating it, and the ways their experience in the classroom led them to view and (sometimes) revise it. We envision the essays as serving two functions: first, we wanted to show the intellectual work, distinct from but parallel in rigor to other kinds of academic textual production, that is central to assignment design. Second, we want our authors' narratives to invite both disciplinary insiders and outsiders into their worlds, creating the kinds of cross-pollination we experience as so fruitful in our WID work.

Working on these essays with authors and reviewers to prepare this first issue of Prompt opened an engaging dialogue between writing studies and other fields. It also underlined that writing studies is, while cross-disciplinary, rooted sufficiently in the humanities that more significant translation and explanation seems necessary in engaging with social scientific and scientific work. For this issue, we typically offered two reviews for each piece: one from the assignment-writer's discipline, and a second from writing studies. These reviews aligned closely with one another for pieces within the humanities, and diverged more and more as we moved closer to the natural sciences. What constituted "writing" in a field? Or "revision," or even "drafting?" Foundational practical questions like this, 
relatively uncomplicated for humanistic pieces, became more complex and interesting as we moved towards the sciences. We realized that, while writing studies is broad indeed, our process of working across disciplines in this issue suggested that a forum like this, in which scholars in diverse disciplines can speak for themselves as to what writing and the teaching of it are, was a worthwhile endeavor.

At the same time, our multidisciplinary process for this issue suggested that pedagogical challenges sometimes cut across disciplinary lines, as do possible responses to those challenges. Further, the need to showcase and promote excellent writing assignments is not restricted to particular disciplines; writing, of one kind or another, is fundamental for learning and sharing knowledge in all scholarly disciplines, and our teaching should reflect that. In terms of discipline, then, we intentionally set no limits, and here, we have published, and plan to continue to publish, assignments that are part of writing curricula and writing-focused courses as well as those from courses in which other disciplinary content is the primary object of study.

This first issue presents work from the fields of cultural anthropology, history, mathematics, and writing studies. All of these authors have specific things to say to their disciplinary colleagues while also offering insights that are relevant for those outside the field. Gordon Mantler, writing about a history assignment taught in a first-year seminar, reminds readers within his field of the challenges of teaching students how to critically encounter the key objects of study in a history. Our disciplines tend to offer default ways in which such knowledge is shared with students, and Mantler's work demonstrates the value of critically rethinking those default modes, regardless of our disciplinary location.

In another essay in this issue, Michael Ennis tackles an issue increasingly confronting many instructors in the field of writing studies: how can instructors balance the need to give students experiences composing the multimedia texts so commonly consumed within our daily lives, like online videos, with the competing requirement of preparing students to write linear, clear prose of the kind typically valued within academic writing? His solution makes clear that these two goals should, and can, be interrelated in a compelling way. Faculty from different fields will recognize some version of this dilemma-preparing students to communicate inside the university and outside it - and his way of thinking about this challenge speaks broadly to that concern.

As for innovation, we intend for each assignment we publish to have something original to contribute to the pedagogical conversation, and this issue showcases innovation of two types. The first is the author who tackles a traditional type of writing assignment in a fresh, compelling way. For example, Lowell Abrams writes in this issue about the proof in mathematics, a type of writing with which any student of math will be familiar. He reimagines the approach to this staple assignment for the field, suggesting changes that focus students on the intellectual work of math through revision. His insight could offer much to the way mathematics is taught in a wide array of classes.

Likewise, Laurie Grobman, in writing studies, writes about a service learning course which allowed writers to compose texts of immediate, pragmatic use in their community. 
The policy briefs written by her students and shared with local municipal collaborators exemplify a common type of service learning writing assignment. Her writing in this issue explores, directly and frankly, the very real challenges of leading student writers, and their writing, outside of the university.

The second kind of innovation we seek to share are unique assignments that create a writing situation largely unlike those we are used to seeing. In this issue, cultural anthropologist Dwayne Dixon draws on a new web-based composing environment, Scalar, to create a collaborative, non-linear writing project that reminds us of the many assumptions we make about what an undergraduate writing assignment looks like in our fields. His work charts new possibilities, and it chronicles the benefits and challenges of asking students to write in ways and forms that will be very new to them.

In publishing the assignments themselves alongside the essays about them, we have treated them largely as artifacts, making minor editorial changes so that they are intelligible to readers outside the classroom in which they were assigned, but not substantially revising the assignment from the form it took when it was taught. The impetus here comes from both our commitment to presenting the real work of teaching writing and the thinking of real and particular teachers, and from our interest in highlighting rather than minimizing disciplinary diversity.

As we hope this short introductory essay shows, one of the real pleasures of putting together this first issue was collaborating with our contributors across disciplines, conversing and imagining with them what might be accomplished if their best work were to be presented as an interdisciplinary, polyvocal dialogue. We are grateful to them, and excited to invite you, as you turn the (digital) page, to participate in this dialogue yourself.

We would like to thank Associate Editor Holly Ryan for her invaluable editorial work on this essay and the issue as a whole. This project could not have reached its current form without her energy, intellect, and enthusiasm. 